\title{
Pericardial Effusion and Cardiac Tamponade: Etiology and Evolution in the Contemporary Era
}

Claudio Martins de Queiroz, ${ }^{\circledR}$ Juliano Cardoso, ${ }^{2}$ Felix Ramires, ${ }^{2}{ }^{\circledR}$ Barbara lanni, ${ }^{2}{ }^{\circledR}$ Viviane Tiemi Hotta, ${ }^{2}$ Charles Mady, ${ }^{2}$ Paula de Cassia Buck, ${ }^{2}{ }^{\circledR}$ Ricardo Ribeiro Dias, ${ }^{2}{ }^{\circledR}$ Luciano Nastari, $^{2}$ Fábio Fernandes ${ }^{2} \odot$

Universidade Cidade de São Paulo, ${ }^{1}$ São Paulo, SP - Brazil

Universidade de São Paulo - Instituto do Coração, ${ }^{2}$ São Paulo, SP - Brazil

\section{Abstract}

Background: Pericardial effusion is a relatively common finding and can progress to cardiac tamponade; etiological diagnosis is important for guiding treatment decisions. With advances in medicine and improvement in the social context, the most frequent etiological causes have changed.

Objectives: To evaluate the clinical and laboratory characteristics, etiology, and clinical course of patients with pericardial effusion and cardiac tamponade.

Materials and methods: Patients with pericardial effusion classified as small $(<10 \mathrm{~mm})$, moderate (between 10-20 mm), or severe $(>20 \mathrm{~mm})$ were included. Data from the clinical history, physical examination, laboratory tests, and complementary tests were evaluated in patients with pericardial effusion and cardiac tamponade. The significance level was set at $5 \%$.

Results: A total of 254 patients with a mean age of $53.09 \pm 17.9$ years were evaluated, $51.2 \%$ of whom were female. A total of $40.4 \%$ had significant pericardial effusion ( $>20 \mathrm{~mm}$ ). Pericardial tamponade occurred in $44.1 \%$ of patients. Among pericardial effusion patients without tamponade, the most frequent etiologies were: idiopathic (44.4\%) and postsurgical (17.6\%), while among those with tamponade, the most frequent etiologies were postsurgical $(21.4 \%)$ and postprocedural (19.6\%). The mean follow-up time was 2.2 years. Mortality was $42 \%$ and 23.2 in those with and without tamponade, respectively $(\mathrm{p}=0.001)$.

Conclusions: There is an etiological difference between pericardial effusion patients with and without cardiac tamponade. An idiopathic etiology is more common among those without tamponade, while postinterventional/postsurgical is more common among those with tamponade. The tamponade group had a higher mortality rate.

Keywords: Pericardium; Pericarditis; Cardiac Tamponade/therapy; Pericardial Effusion/therapy.

\section{Introduction}

Pericardial effusion is a common finding in clinical practice and could be due to systemic disease or a cardiac problem. Some patients with pericardial effusion also have cardiac tamponade, which is characterized by a drop in cardiac output, jugular venous distension, muffled heart sounds, arterial hypotension, and systemic hypoperfusion. Cardiac tamponade is a serious condition that requires rapid intervention..$^{1-8}$

Some of the etiologies of pericardial effusion include neoplasm, infection, and tuberculosis in developing countries. It has been closely related to immunodepression, iatrogenesis, connective tissue diseases, and postsurgical complications. Moreover, the etiology of many patients is idiopathic. ${ }^{1}$ There has been a significant increase in cardiac procedures in recent decades, both diagnostic and therapeutic, in addition to the more frequent use of anticoagulants or antiplatelet agents. This has led to an increased incidence of pericardial effusion after procedures such as cardiac catheterization, angioplasty, arrhythmia ablation, and implantation of pacemakers and percutaneous prostheses. ${ }^{1,9-14}$ 
The most frequent etiologies differ depending on the type of cohort studied, as well as the region where in which the study was conducted. In addition, with advances in medicine and improvement in the social context, the most frequent etiologies have changed. ${ }^{1-10}$ The present study, conducted at a tertiary cardiology center, selected patients who had pericardial effusion with or without cardiac tamponade and evaluated their clinical, laboratory, and etiological characteristics, in addition to their clinical course.

\section{Material and methods}

This retrospective cohort study included patients diagnosed with pericardial effusion with or without cardiac tamponade who were treated in the outpatient or inpatient unit of a tertiary cardiology center in the city of São Paulo between March 2007 and March 2018. The inclusion criteria were a diagnosis of pericardial effusion with or without cardiac tamponade. The included patients were admitted through the Brazilian Unified Health System. We assessed the patients' medical records and contacted them to assess survival. From the medical records, we evaluated clinical data (blood pressure, heart rate, jugular venous distension, pericardial friction, paradoxical pulse, Kussmaul's sign, edema, and ascites), laboratory data, and echocardiography, as well as pericardial biopsy and analysis of pericardial fluid in patients with cardiac tamponade. At the discretion of the attending physician, pericardial biopsy was indicated for patients with refractory recurrent pericarditis, as well as those with suspected neoplastic disease or tuberculosis. We also evaluated postprocedural complications, which were defined as pericardial effusion or tamponade after an angioplasty, ablation, or pacemaker procedure. Patients with recurrent pericardial effusion or tamponade were also evaluated.

The size of the pericardial effusion was quantified with two-dimensional echocardiography and was divided into small effusion (size in the $\mathrm{M}$ mode $<10 \mathrm{~mm}$ and visualized only in the posterior part of the left ventricle), moderate (size between 10 and $20 \mathrm{~mm}$ and encompassing the entire heart), or major (echo-free spaces $>20 \mathrm{~mm}) .{ }^{7}$ Cardiac tamponade was diagnosed using the clinical picture (decreased cardiac output, hypotension, muffled heart sounds, jugular venous distension, hypoperfusion) and echocardiogram to confirm the presence of pericardial effusion. All echocardiograms were performed at our service.
This study was approved by the Ethics Committee of the Hospital das Clínicas of the University of São Paulo Faculty of Medicine (CAPPesq: 2,885,227, 11/09/2018).

\section{Statistical analysis}

Initially, all variables were analyzed descriptively. Quantitative variables were analyzed as minimum and maximum values and by calculating the mean and standard deviation. For qualitative variables, absolute and relative frequencies were calculated. Data normality was assessed using the Kolmogorov-Smirnov test. An unpaired Student's $t$-test was used to compare means between the two groups. The chi-square test or Fisher's exact test was used to test homogeneity. The Kaplan-Meier curve was used to study survival. SPSS 17.0 was used for the calculations; a 5\% significance level was used for the tests.

\section{Results}

A total of 254 patients (mean age 53.09 [SD,17.9] years; $51.2 \%$ female) diagnosed with pericardial effusion or cardiac tamponade were included. Table 1 lists the patients' clinical characteristics. A total of $40.4 \%$ of the patients had a significant pericardial effusion $(>20 \mathrm{~mm})$ and 112 (44.1\%) had cardiac tamponade. The group with tamponade had a higher percentage of effusion $>20 \mathrm{~mm}$ than the group without tamponade (Table 2). The group with tamponade had a significantly higher percentage of complications, such as jugular venous distension, pericardial friction, paradoxical pulse, Kussmaul's sign, and muffled heart sounds. Table 3 compares the group characteristics.

In the overall sample, idiopathic pericardial effusion was the most frequent etiology (84 patients, 33.1\%), followed by postsurgical (49 patients, $19.3 \%$ ), neoplastic (43 patients, $16.9 \%$ ), and postprocedural complications (angioplasty, ablation and pacemaker)(22 patients, $8.7 \%$ ). Table 4 shows all observed etiologies. When the etiologies were compared according to the presence or absence of tamponade, the most frequent ones in the group without tamponade were idiopathic (44.4\%), post-cardiac surgery (17.6\%), and neoplasm $(16.2 \%)$, whereas in the group with tamponade, the most frequent etiologies were postsurgical (21.4\%), postprocedural (19.6\%), idiopathic $(18.8 \%)$, and neoplastic (17.9\%) (Table 5).

When the groups were compared regarding the need for pericardiocentesis, recurrence, and medication type, 
Table 1 - Clinical and demographic characteristics of the total population

\begin{tabular}{lc}
\hline Variable & $(\mathbf{n}=\mathbf{2 5 4})$ \\
\hline Age years (mean \pm SD) & $53.09 \pm 17.95$ \\
Female n (\%) & $130(51.2)$ \\
Hypertension n (\%) & $120(49.2)$ \\
Diabetes n (\%) & $53(21.7)$ \\
Jugular venous distension n (\%) & $99(42.7)$ \\
Pericardial friction n (\%) & $28(12.1)$ \\
Paradoxical pulse n (\%) & $63(27.3)$ \\
Kussmaul's sign n (\%) & $64(27.7)$ \\
Muffled heart sounds n (\%) & $95(41.1)$ \\
Edema n (\%) & $71(30.7)$ \\
Systolic blood pressure mmHg (SD) & $119.27(25.01)$ \\
Heart rate, mean (SD) & $88.94(22.31)$ \\
Ascites n (\%) & $8(3.5)$ \\
\hline
\end{tabular}

Table 2 - Classification of effusion by echocardiography according to the patient's clinical condition (presence or absence of clinical tamponade)

\begin{tabular}{|c|c|c|c|c|}
\hline \multirow{2}{*}{ Variable } & \multirow{2}{*}{$(\mathrm{n}=254)$} & \multicolumn{2}{|c|}{ Cardiac tamponade } & \multirow{2}{*}{$\mathrm{p}$} \\
\hline & & No $(n=142)$ & Yes $(n=112)$ & \\
\hline Pericardial effusion n (\%) & & & & $0.042^{*}$ \\
\hline$<10$ & $75(29.8)$ & $39(27.6)$ & $36(32.4)$ & \\
\hline $10-20$ & $75(29.8)$ & $51(36.2)$ & $24(21.6)$ & \\
\hline$>20$ & $102(40.4)$ & $51(36.2)$ & $51(46.0)$ & \\
\hline
\end{tabular}

the group with tamponade had a significantly higher percentage of pericardiocentesis and death (Table 6). The overall mortality rate was $31.5 \%$ (80 patients), being significantly higher in the group with tamponade (42\%) than the group without it $(23.2 \%)(\mathrm{P}=0.001)$. Patient follow-up time ranged from 0 days to 10.5 years (mean 2.22 years, SD 2.70 years; median 1.07 years). According to the Kaplan-Meyer curve, there was a significant difference in survival time between the groups (log rank test: $\mathrm{P}=0.004)$, which was shorter in the group with tamponade (Figure 1).

\section{Discussion}

The most frequent etiologies of pericardial effusion in our sample were idiopathic, followed by post-cardiac surgery and neoplastic. However, when we separated the groups according to the presence or absence of cardiac tamponade, the most frequent etiology in patients without tamponade was idiopathic, followed by postcardiac surgery and neoplastic, similar to the general group. However, in those with tamponade, the most frequent etiology was post-cardiac surgery, followed by 
Table 3 - Clinical and demographic differences between patients with and without cardiac tamponade

\begin{tabular}{|c|c|c|c|c|}
\hline \multirow{2}{*}{ Variable } & \multirow{2}{*}{$(\mathrm{n}=254)$} & \multicolumn{2}{|c|}{ Cardiac tamponade } & \multirow{2}{*}{$\mathrm{p}$} \\
\hline & & No $(n=142)$ & Yes $(n=112)$ & \\
\hline Age years (mean + SD) & $53.09(17.95)$ & $51.54 \pm 17.70$ & $55.06 \pm 18.16$ & $0.120^{*}$ \\
\hline Female n (\%) & $130(51.2)$ & $74(52.1)$ & $56(50.0)$ & $0.738^{+}$ \\
\hline Hypertension n (\%) & $120(49.2)$ & $66(49.3)$ & $54(49.1)$ & $0.980^{+}$ \\
\hline \multicolumn{2}{|l|}{ Diabetes n (\%) } & & & $0.690^{\S}$ \\
\hline Yes & $53(21.7)$ & $29(21.6)$ & $24(21.8)$ & \\
\hline Previous pericarditis n (\%) & $15(6.2)$ & $13(9.7)$ & $2(1.8)$ & $0.011^{+}$ \\
\hline Fever n (\%) & $20(8.2)$ & $13(9.7)$ & $7(6.4)$ & $0.344^{+}$ \\
\hline Radiotherapy n (\%) & $14(5.7)$ & $6(4.4)$ & $8(7.3)$ & $0.336^{+}$ \\
\hline Mean height (SD) & $163.07(12.45)$ & $163.10(11.74)$ & $163.04(13.35)$ & $0.971^{*}$ \\
\hline Mean weight (SD) & $70.25(18.70)$ & $69.66(18.82)$ & $71.03(18.61)$ & $0.577^{*}$ \\
\hline Mean BMI (SD) & $26.01(5.79)$ & $25.93(5.99)$ & $26.11(5.55)$ & $0.821^{*}$ \\
\hline Jugular venous distension $\mathrm{n}(\%)$ & 99 (42.7) & $44(34.1)$ & $55(53.4)$ & $0.003^{+}$ \\
\hline Pericardial friction n (\%) & $28(12.1)$ & $4(3.1)$ & $24(23.3)$ & $<0.001^{+}$ \\
\hline Paradoxical pulse n (\%) & $63(27.3)$ & $8(6.3)$ & $55(53.4)$ & $<0.001^{+}$ \\
\hline Kussmaul's sign n (\%) & $64(27.7)$ & $16(12.5)$ & $48(46.6)$ & $<0.001^{+}$ \\
\hline Muffled heart sounds n (\%) & $95(41.1)$ & $32(25.0)$ & $63(61.2)$ & $<0.001^{+}$ \\
\hline Edema n (\%) & $71(30.7)$ & $39(30.5)$ & $32(31.1)$ & $0.922^{+}$ \\
\hline Mean SBP (SD) & $119.27(25.01)$ & $122.29(21.85)$ & $115.76(27.95)$ & $0.070^{*}$ \\
\hline Mean DBP (SD) & $73.45(15.05)$ & $76.51(13.91)$ & $69.92(15.61)$ & $0.002^{*}$ \\
\hline Mean HR (SD) & $88.94(22.31)$ & $88.38(17.88)$ & $89.64(26.83)$ & $0.694^{*}$ \\
\hline Ascites n (\%) & $8(3.5)$ & $4(3.1)$ & $4(3.9)$ & $1.000^{\S}$ \\
\hline $\begin{array}{l}\text { *Student's } \text { t-test - descriptive probo } \\
\text { + Chi-square test - descriptive prob } \\
\text { † Likelihood ratio test - descriptive } \\
\text { §Fisher's exact test - descriptive pr }\end{array}$ & $\begin{array}{l}\text { vel } \\
\text { evel } \\
\text { ity level } \\
\text { level }\end{array}$ & & & \\
\hline
\end{tabular}

postprocedural, idiopathic, and neoplastic. Mortality was higher in the group with cardiac tamponade.

The frequency of pericardial effusion etiologies varies in the literature according to geographic distribution, selection criteria, and type of medical service, ie, a tertiary, secondary, or primary reference center. We found a number of different etiologies for pericardial effusion. ${ }^{6}$ Corey et al., ${ }^{7}$ evaluated 57 patients with pericardial effusion $>10 \mathrm{~mm}$, finding that the most frequent etiology was infectious $(27 \%)$, followed by neoplastic (23\%). In a study of 322 patients with pericardial effusion $>10 \mathrm{~mm}$ by Sagrista et al. ${ }^{8}$ the most frequent etiology was idiopathic (29\%), followed by iatrogenic $(16 \%)$, and neoplastic $(13 \%) ; 37 \%$ of the sample had cardiac tamponade. A 2003 study by Levy et al., evaluated 204 patients with pericardial effusion, and the most frequent etiologies were idiopathic (48\%), infectious (16\%), and neoplastic (15\%). In our study of 254 patients with pericardial effusion, most had an idiopathic etiology $(33.1 \%)$, followed by postsurgical $(19.3 \%)$, neoplastic $(16.9 \%)$ and postprocedural $(8.7 \%)$. However, when patients with and without tamponade were analyzed separately, we found a difference in etiology: in patients without tamponade, the most frequent causes were 
Table 4 - Etiology of pericardial effusion and cardiac tamponade: overall study population

\begin{tabular}{|c|c|}
\hline Etiology & $\begin{array}{c}(\mathrm{n}=254) \\
\mathrm{n}(\%)\end{array}$ \\
\hline Idiopathic & $84(33.1)$ \\
\hline Post-cardiac surgery & 49 (19.3) \\
\hline Cancer & $43(16.9 \%)$ \\
\hline Lung neoplasm & $19(7.5)$ \\
\hline Breast neoplasm & $5(2.0)$ \\
\hline Lymphoma & $6(2.4)$ \\
\hline Other neoplasms & $13(5.1)$ \\
\hline Postprocedural & $22(8.7)$ \\
\hline Collagenous & $13(5.1)$ \\
\hline Tuberculosis & $13(5.1)$ \\
\hline Post-acute myocardial infarction & $7(2.8)$ \\
\hline Renal & $6(2.4)$ \\
\hline Bacterial & $6(2.4)$ \\
\hline Acquired immunodeficiency syndrome & $5(2.0)$ \\
\hline Aortic dissection & $3(1.2)$ \\
\hline Hypothyroidism & $2(0.8)$ \\
\hline Chylopericardium & $1(0.4)$ \\
\hline
\end{tabular}

Table 5 - Relationship between etiology and the presence or absence of tamponade

\begin{tabular}{lccc}
\hline & & \multicolumn{2}{c}{ Cardiac tamponade } \\
\cline { 3 - 3 } Variable & $(\mathbf{n}=\mathbf{2 5 4 )}$ & $\mathbf{N o}(\mathbf{n}=\mathbf{1 4 2})$ & Yes (n=112) \\
\hline Etiology & $\mathrm{n}(\%)$ & $\mathrm{n}(\%)$ & $\mathrm{n}(\%)$ \\
Tuberculosis & $13(5.1)$ & $8(5.6)$ & $5(4.5)$ \\
Cancer & $43(16.9)$ & $23(16.2)$ & $20(17.9)$ \\
Collagenous & $13(5.1)$ & $7(4.9)$ & $6(5.4)$ \\
Postprocedural & $22(8.7)$ & $0(0.0)$ & $22(19.6)$ \\
Postsurgical/pericardiectomy & $49(19.3)$ & $25(17.6)$ & $24(21.4)$ \\
Idiopathic & $84(33.1)$ & $63(44.4)$ & $21(18.8)$ \\
Other & $30(11.8)$ & $16(11.3)$ & $14(12.5)$ \\
\hline
\end{tabular}


Table 6 - Absolute frequencies (\%) of the variables (intervention and recurrence) in the clinical course of 254 patients according to the presence or absence of tamponade

\begin{tabular}{|c|c|c|c|c|}
\hline \multirow{2}{*}{ Variável } & \multirow{2}{*}{$(n=254)$} & \multicolumn{2}{|c|}{ Cardiac tamponade } & \multirow{2}{*}{$\mathrm{p}^{*}$} \\
\hline & & No $(n=142)$ & Yes $(n=112)$ & \\
\hline Pericardiocentesis & $194(76.4)$ & 99 (69.7) & $95(84.8)$ & 0.005 \\
\hline Recurrence & $14(5.5)$ & $8(5.6)$ & $6(5.4)$ & 0.924 \\
\hline Non-hormonal anti-inflammatory & $188(74.0)$ & $100(70.4)$ & $88(78.6)$ & 0.142 \\
\hline Colchicine & $34(13.4)$ & $23(16.2)$ & $11(9.8)$ & 0.138 \\
\hline Corticoid & $111(43.7)$ & $60(42.3)$ & $51(45.5)$ & 0.601 \\
\hline Death & $80(31.5)$ & $33(23.2)$ & $47(42.0)$ & 0.001 \\
\hline
\end{tabular}

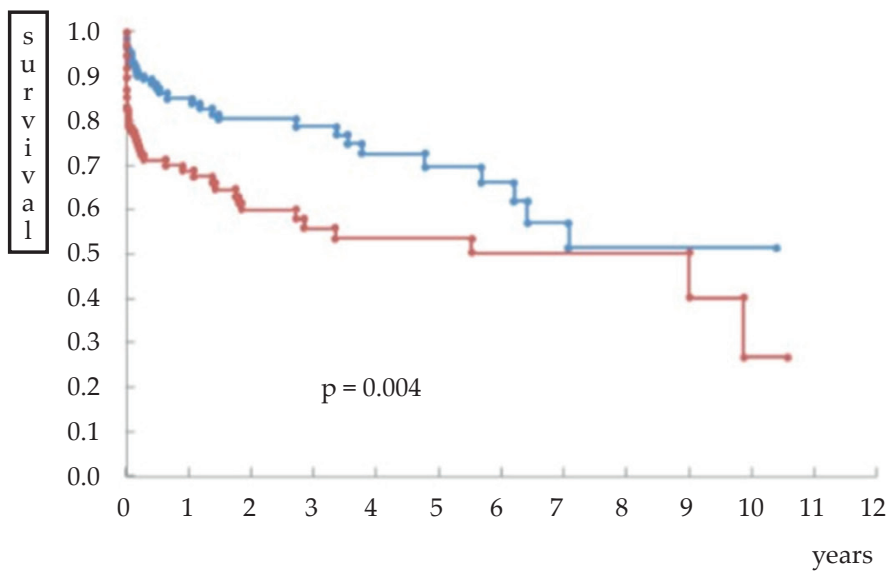

Cardiac tamponade

No $\longrightarrow$

Yes $\longrightarrow$

Figure 1 - Kaplan-Meier survival curve according to the presence or absence of cardiac tamponade. (Yes = with tamponade; $N o=$ without tamponade)

idiopathic (44.4\%), postsurgical (17.6\%), and neoplastic $(16.2 \%)$, whereas in patients with tamponade, the most frequent causes were postprocedural (19.6\%), idiopathic $(18.8 \%)$, and neoplastic (17.9\%).

Our study found that cardiac procedures, such as angioplasty, pacemaker implantation and arrhythmia ablation, are important in the etiology of cardiac tamponade, and these procedures are increasingly performed. Recent studies indicate the growth of this etiology. A 2016 study by Orbach et al., ${ }^{10}$ of patients with cardiac tamponade found that the main etiology was percutaneous cardiac intervention (36\%), followed by neoplasia $(23 \%)$, infectious and inflammatory causes $(15 \%)$, and mechanical complications of myocardial infarction (12\%).

In cancer patients, pericardial effusion can develop through various mechanisms, such as direct extension or metastatic dissemination, or as a complication of systemic tumor treatment with radiotherapy and chemotherapy, although it may also be due to an opportunistic infection. Thus, neoplastic diseases are a significant etiology of pericardial effusion or tamponade. ${ }^{11-16}$ In our study, 
neoplasia was a frequent cause of pericardial effusion, with or without cardiac tamponade. This etiology was found in $43(16.9 \%)$ of our patients, the most frequent types being lung cancer (44.2\%), lymphoma (13.9\%), and breast cancer (11.6\%). In a 2013 review article by Burazor et al., ${ }^{11}$ pulmonary effusion varied between $34 \%$ and $76 \%$ in cancer patients, with breast cancer as the etiology in $15 \%$ to $17 \%$. We should be aware that pericardial effusion can be one of the first manifestations of cancer, and pericardial fluid analysis and biopsy can be the key to diagnosing the primary tumor.

Despite progressive improvement in tuberculosis prevention, this etiology is still prevalent in our country. In tuberculous pericarditis, a bacillus is found upon direct examination in only $40 \%$ to $60 \%$ of patients undergoing pericardiocentesis. High adenosine deaminase activity is also diagnostic, with high sensitivity and specificity. ${ }^{2}$ Our data showed an overall incidence of approximately $5.1 \%$. An etiology of tuberculosis is highly dependent on region. In a review article by Mayosi ${ }^{21}$, tuberculosis was the etiology in $69.5 \%$ of African pericardial effusion cases, compared to $3.8 \%$ in non-African countries. ${ }^{22-23}$ Our results were comparable to non-African countries.

In evaluating the clinical course of patients, mortality is related to etiology and the presence or absence of tamponade. Our study found an overall mortality of $31.5 \%$ during follow-up, with a significantly higher mortality rate in patients with tamponade (42\% vs. $23.2 \%$ $\mathrm{p}=0.001)$. We observed a new scenario for the etiology and clinical course of pericardial effusion. Burazor et al., ${ }^{11}$ highlighted the correlation between pericardial effusion and worse prognosis in cancer patients in their review of studies conducted between 1977 and 2007: 86\% of cancer patients with pericardial effusion died in the first year and almost one-third died in the first month. It should be pointed out, however, that cancer therapy was not very advanced early in the review period. ${ }^{11}$ A 2016 study by Orbach et al., ${ }^{10}$ of patients with pericardial effusion of various etiologies found that patients with iatrogenic pericardial effusion had a favorable evolution compared to those whose pericardial effusion was due to neoplasia, coagulation disorder, or infarction. These authors found the following mortality rates for hospitalized pericardial effusion patients according to etiology (total number; mortality after 30 days and 1 year of follow-up, respectively): inflammatory and infectious $(8.3 \% ; 16.7 \%$ and $16.7 \%)$, postsurgical complication
(10.3\%; $13.8 \%$ and $17.20 \%)$, neoplasia $(15.8 \% ; 36.8 \%$ and $68.4 \%$ ), coagulopathy and bleeding $(40 \%$; $60 \%$ and $80 \%$ ), and infarction (70\%; $80 \%$ and $80 \%$ ). This disease still has a high mortality rate, especially in cases of cardiac tamponade.

\section{Study limitations}

This single-center study was conducted in a tertiary hospital and based on the analysis of medical records. Although all echocardiograms were performed in our service, it should be pointed out that they were not performed by the same observer, which could have biased the classification of pericardial effusion. Due to the convenience sampling and lack of sample size estimation, any statistical inferences are exploratory.

\section{Conclusions}

In the present study, which was carried out in a tertiary cardiology hospital, the most frequent etiologies were idiopathic, followed by post-cardiac surgery, neoplastic, and as a postprocedural complication. A significant percentage of the patients $(44.1 \%)$ had cardiac tamponade. Among those without tamponade, the most frequent etiologies were idiopathic, postsurgical, and neoplastic, while among those with tamponade, the most frequent etiologies were postsurgical, post-procedural, idiopathic, and neoplastic. Mortality was high overall (31.5\%) and significantly higher in the group with tamponade. Patients with tamponade had shorter survival than those without it.

\section{Author contributions}

Conception and design of the research: Queiroz CM, Cardoso J, Fernandes F. Acquisition of data: Queiroz CM, Cardoso J, Dias RR, Mady C. Analysis and interpretation of the data: Queiroz CM, Cardoso J. Statistical analysis: Cardoso J. Writing of the manuscript: Queiroz CM, Cardoso J, Ramires FJA, Ianni BM, Buck PC. Critical revision of the manuscript for intellectual content: Cardoso J, Ramires FJA, Ianni BM, Hotta VT, Buck PC, Dias RR, Mady C, Fernandes F.

\section{Potential Conflict of Interest}

No potential conflict of interest relevant to this article was reported. 


\section{Sources of Funding}

There were no external funding sources for this study.

\section{Study Association}

This study is not associated with any thesis or dissertation work.

\section{References}

1. Adler Y, Charron P, Imazio M, Badano L, Barón-Esquivias G, Bogaert J, et al. 2015 ESC Guidelines for the diagnosis and management of pericardial diseases: The Task Force for the Diagnosis and Management of Pericardial Diseases of the European Society of Cardiology (ESC) Endorsed by: The European Association for Cardio-Thoracic Surgery (EACTS). Eur Heart J. 2015;36:2921-64.

2. Montera MW, Mesquita ET, Colafranceschi AS, Oliveira Junior AM, Rabischoffsky A, Ianni BM, et al. I Diretriz brasileira de miocardites e pericardites. Arq Bras Cardiol. 2013;100(4, supl. 1):1-36.

3. Fernandes F, Ianni BM, Mesquita ET. Doenças do pericárdio. In: KalilFilho R; Fuster V. (Org.). Medicina cardiovascular: reduzindo o impacto das doenças. 1ed.São Paulo: Atheneu, 2016, v. 2, p. 1297-1322.

4. Pêgo-Fernandes PM, Fernandes F, Ianni BM, Faria GF. Derrame pericárdico: manejo diagnóstico e terapêutico. In: Camargo JJ, Pinto-Filho DR (Org.). Cirurgia torácica contemporânea. 1ed.Rio de Janeiro: Thieme Revinter, 2019, v. 1, p. 247-250.

5. Pêgo-Fernandes PM, Fernandes F, Ianni BM, Faria GF. Pericardite aguda e crônica: manejo terapêutico. In: Cirurgia torácica contemporânea.1 ed.Rio de Janeiro: Thieme Revinter, 2019, v.1, p. 251-255.

6. Imazio M, Spodick DH, Brucato A, Trinchero R, Adler Y. Controversial issues in the management of pericardial diseases. Circulation. 2010;121(7):916-28.

7. Corey GR, Campbell PT, Van Trigt P, Kenney RT, O'Connor CM, Sheikh KH, et al. Etiology of large pericardial effusions. Am J Med. 1993;95(2):209-13.

8. Sagrista-Sauleda J, Merce J, Permanyer-Miralda G, Soler-Soler J. Clinical clues to the causes of large pericardial effusions. Am J Med. 2000;109(2):95-101.

9. Levy PY, Corey R, Berger P, Habib G, Bonnet JL, Levy S, et al. Etiologic diagnosis of 204 pericardial effusions. Medicine (Baltimore). 2003;82(6):385-91.

10. Orbach A, Schliamser JE, Flugelman MY, Zafrir B. Contemporary evaluation of the causes of cardiac tamponade: Acute and long-term outcomes. 2016;23(1):57-63.

11. Burazor I, Imazio M, Markel G, Adler Y. Malignant pericardial effusion. Cardiology, 2013;124(4):224-32.

\section{Ethics approval and consent to participate}

This study was approved by the Ethics Committee of the Hospital das Clínicas da FMUSP under the protocol number 2.885.227. All the procedures in this study were in accordance with the 1975 Helsinki Declaration, updated in 2013. Informed consent was obtained from all participants included in the study.

12. De Ceuninck M, Demedts I, Trenson S. Malignant cardiac tamponade. Acta Cardiol. 2013;68(5):505-7.

13. Refaat M, Katz W. Neoplastic pericardial effusion. Clin Cardiol. 2011;34(10):593-8.

14. Cornily JC, Pennec PY, Castellant P, Bezon E, Le Gal G, Gilard M, et al Cardiac tamponade in medical patients: A 10-year follow-up survey. Cardiology. 2008;111(3):197-201.

15. Gibbs CR, Watson RDS, Singh SP, Lip GYH. Management of pericardial effusion by drainage: A survey of 10 years' experience in a city centre general hospital serving a multiracial population. Postgrad Med J. 2000;76(902):809-13.

16. Colombo A, Olson HG, Egan J, Gardin JM. Etiology and prognostic implications of a large pericardial effusion in men. Clin Cardiol. 1988;11(6):389-94.

17. Kim SH, Kwak MH, Park S, Kim HJ, Lee HS, Kim MS, et al: Clinical characteristics of malignant pericardial effusion associated with recurrence and survival. Cancer Res Treat. 2010;42(4):210-6.

18. Gornik H, Gerhard-Herman M, Beckman J. Abnormal cytology predicts poor prognosis in cancer patients with pericardial effusion. J Clin Oncol. 2005;23(221):5211-6.

19. García-Riego A, Cuinas C, Vilanova JJ. Malignant pericardial effusion. Acta Cytol. 2001;45(4):561-6.

20. Dequanter D, Lothaire P, Berghmans T, Sculier JP. Severe pericardial effusion in patients with concurrent malignancy: a retrospective analysis of prognostic factors influencing survival. Ann Surg Oncol. 2008;15(11):3268-71.

21. Mayosi BM. Contemporary trends in the epidemiology and management of cardiomyopathy and pericarditis in sub-Saharan Africa. Heart. 2007;93(10):1176-83.

22. Reuter H, Burgess L, van Vuuren W, Doubell A. Diagnosing tuberculous pericarditis. QJM. 2006;99(12):827-39.

23. Imazio M, Cecchi E, Demichelis B, Ierna S, Demarie D, Ghisio A, et al. Indicators of poor prognosis of acute pericarditis. Circulation. 2007;115(21):2739-44. 